\title{
ACTIVITIES OF THE HEADQUARTERS FOR EARTHQUAKE RESEARCH PROMOTION
}

\author{
Sadanori HIGASHI ${ }^{1}$ \\ ${ }^{1}$ Member of JAEE, Earthquake and Disaster-Reduction Research Division, Research Development \\ Bureau, Ministry of Education, Culture, Sports and Technology (MEXT), Japan \\ higashi@mext.go.jp
}

\begin{abstract}
After the Great Hanshin-Awaji Earthquake of 1995, the Headquarters for Earthquake Research Promotion was established as a special government organization. It has been promoting the following earthquake research: (1) creation of seismic hazard maps, (2) real-time transmission of earthquake information, (3) improvement of observation and other research in the areas and vicinities of intensified earthquake disaster prevention measures determined by the Special Measure Law on Earthquake Disaster Prevention, (4) improved observation and research for earthquake prediction.
\end{abstract}

Key Words: The Headquarters for Earthquake Research Promotion, seismic hazard map, seismic activity, long-term evaluation, strong ground motion

\section{INTRODUCTION}

The Great Hanshin-Awaji Earthquake of 1995 killed nearly 6,400 people, and destroyed over 100,000 buildings, bringing to light a number of problems with our national earthquake disaster prevention measures. Following the lessons learned from this disaster, the Special Measure Law on Earthquake Disaster Prevention was enacted in July 1995 to implement a comprehensive national policy on earthquake disaster prevention. The failure to sufficiently communicate and apply earthquake research results to the general public, and disaster prevention organizations, highlighted the need for a direct system of accountability in governmental policy regarding earthquakes. Therefore the Headquarters for Earthquake Research Promotion, a special government organization attached to the Prime Minister's office, which now belongs to the Ministry of Education, Culture, Sports, Science and Technology, was established in accordance with this law.

In this paper, we report the activities of the Headquarters for Earthquake Research Promotion.

\section{PRIMARY OBJECTIVE AND ROLES}

\section{Primary objective}

To promote research into earthquakes with the goal of strengthening disaster prevention measures, particularly the reduction of damage and casualties from earthquakes. 


\section{Roles}

1. Planning both basic and comprehensive policies

2. Coordination of budgets and other administrative duties with related government organizations

3. Establishment of survey and observation plans

4. Collection, arrangement, analysis and evaluation of survey results by related government organizations, universities, etc.

5. Public announcements based on these evaluations

\section{STRUCTURE OF THE HEADQUARTERS FOR EARTHQUAKE RESEARCH PROMOTION}

The Headquarters for Earthquake Research Promotion is comprised of the director (Minister of Education, Culture, Sports, Science and Technology) and the committee (vice ministers from related ministries and agencies). Beneath them are the Policy Committee and Earthquake Research Committee, each composed of a staff from related government offices and academia.

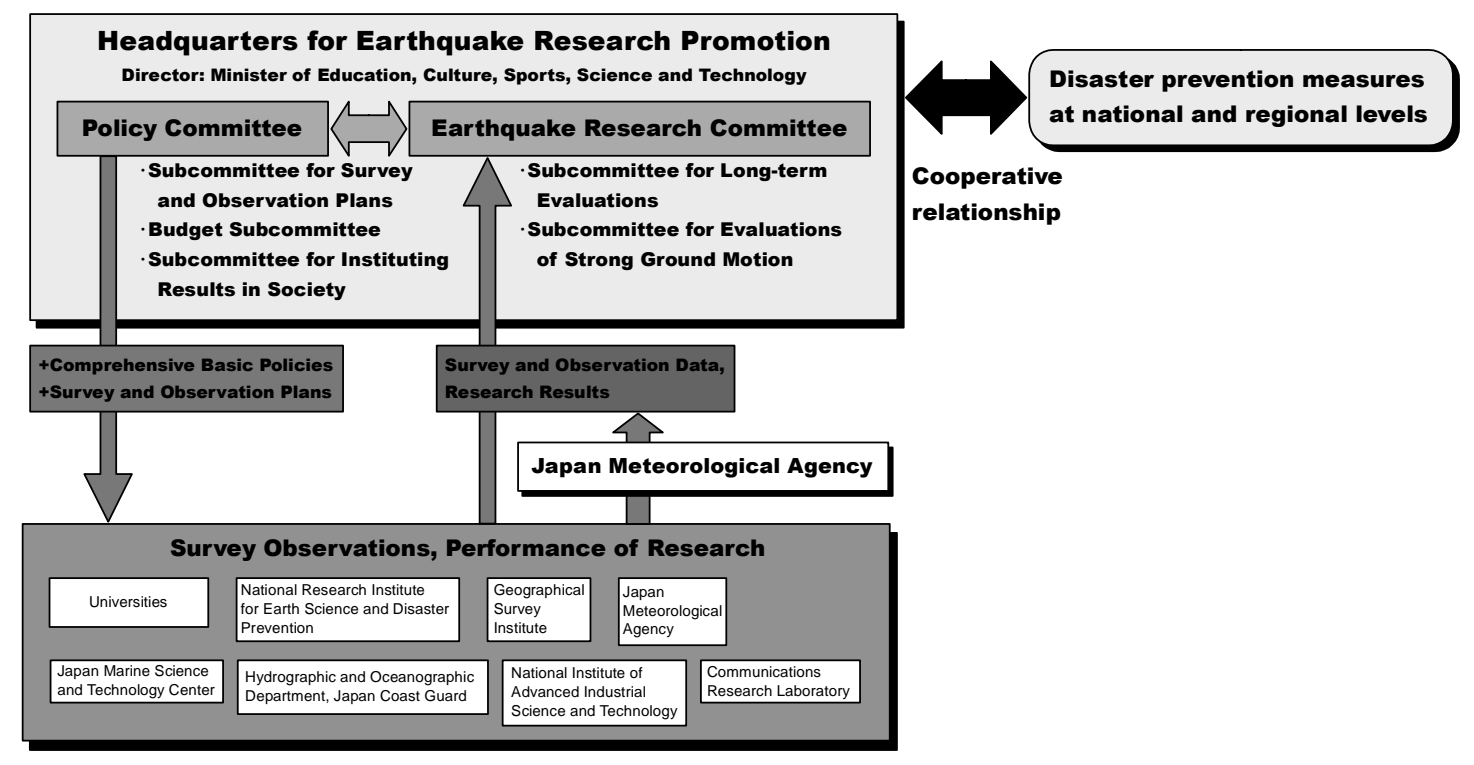

Fig.1 Structure of the Headquarters for Earthquake Research Promotion

\section{BASIC POLICY}

In April 1999 the Headquarters for Earthquake Research Promotion established its fundamental mission statement governing research over the next decade as "The promotion of earthquake research comprehensive basic policies for the promotion of seismic research through the observation, measurement, and survey of earthquakes -" (The Headquarters for Earthquake Research Promotion, 1999).

The main issues related to the earthquake research that must be promoted by the national government in the immediate future are as follows:

1. Preparation of maps showing predicted earthquake activity which consolidate surveys of active faults, long-range assessment of the probability of earthquake occurrence, and prediction of strong tremors.

2. Promotion of real-time transmission of earthquake information

3. Improvement of observation and other research in the areas and vicinities of intensified earthquake disaster prevention measures determined by the Special Measure Law on Earthquake Disaster 
Prevention

4. Promotion of observation and research for earthquake prediction

\section{NATIONAL FUNDS USED FOR EARTHQUAKE RESEARCH}

The Headquarters for Earthquake Research Promotion has established a Budget Subcommittee under the Policy Committee to manage and allocate budgets from government offices.

The government budget allocation for the Headquarters for Earthquake Research Promotion for Fiscal Year 2003 is approximately 9.5 billion yen $^{1}$ (initial budget).

\section{PLANS FOR COMPREHENSIVE SURVEY AND OBSERVATION}

The survey and observation of earthquakes provide findings that make it possible to evaluate the kinds of earthquakes that occur in different regions of Japan, and what types of shaking may occur.

Survey and observations are needed for all parts of Japan, without bias or exception. The Headquarters for Earthquake Research Promotion established the Subcommittee for Survey and Observation Plans under the Policy Committee, which laid down its "Fundamental Plans for Survey and Observation" in 1997 (revised in 2001).

In accordance with these plans, each participating organization is moving forward with setting up high-sensitivity, broadband, strong motion and cable-type ocean bottom seismographs. Along with these various seismographs, they are also setting up a GPS continuous observation facilities. Surveys of inland active faults, crustal structures, and observation of sea floor crustal movements are also being conducted for the entire nation.

In the future, additional emphasis will be placed on survey and observation of areas that have been identified as having a high probability for earthquake occurrence.

\begin{tabular}{|l|l|}
\hline \multicolumn{1}{|c|}{ High-sensitivity seismograph } & \multicolumn{1}{c|}{$\begin{array}{c}\text { Broadband seismograph } \\
\text { A seismograph capable of } \\
\text { registering vibrations across a very } \\
\text { A seismograph capable of } \\
\text { registering very faint shaking } \\
\text { undetectable by humans } \\
\text { rapid to extremely slow }\end{array}$} \\
\hline \multicolumn{1}{|c|}{ Strong motion seismograph } & GPS (Global Positioning System) \\
$\begin{array}{l}\text { A seismograph for recording strong } \\
\text { shaking that would overload high- } \\
\text { sensitibity instruments }\end{array}$ & $\begin{array}{l}\text { A system using satellites to observe } \\
\text { plate motion and crustal movements }\end{array}$ \\
\hline
\end{tabular}

Fig.2 Instruments for comprehensive observation of earthquakes

\section{COMPREHENSIVE EVALUATION OF SEISMIC ACTIVITY}

The Earthquake Research Committee meets every month to collate and analyze survey results compiled by relevant organizations and perform a comprehensive evaluation of seismic activity. These reports are made widely available and contribute to disaster prevention planning at the national and prefectural levels.

In addition, meetings are held in response to damaging earthquakes or marked seismic activity to

\footnotetext{
${ }^{1}$ Excludes a grant of operating costs to independent administrative institution.
} 
assess the current activity and the probability of aftershocks. In 2003 the extraordinary meetings were held on March 26, July 26 and September 26 for the earthquake of offshore Miyagi Prefecture (M7.0) as well as the Northern Miyagi Prefecture (M6.2), and "the Tokachi-oki Earthquake in 2003"(M8.0), respectively.

These monthly and special reports on the evaluation of seismic activity are published on the web site $h t t p: / / w w w . j i s h i n g o . j p / m a i n / i n d e x-e . h t m l$. The committee also issued a report on seismic activity in Japan (The Earthquake Research Committee, 1998).

\section{Long-term evaluations of active faults and earthquakes along the troughs in Japan}

The Earthquake Research Committee evaluates intervals of activity and the potential for the next occurrence by location and scale (magnitude) for major active faults and earthquakes along the trough, and reports the results as they occur. At present (March 2004) out of a total of 98 main fault zones, evaluation reports have been issued for 50 of them. Of the surrounding sea zones, which are divided into nine sectors, evaluation reports have been issued for 7 of them. Figure 3 shows an example of the results of long-term evaluations of the earthquakes along the major fault zones and troughs.

On September 26, 2003, the Tokachi-oki earthquake (M8.0) occurred and caused severe damage in Hokkaido. The probability of this earthquake occurrence in the next 30 years from Jan. 1, 2003 was evaluated to be about $60 \%$ before it occurred (The Earthquake Research Committee, 2003). It was the first major earthquake since the long-term evaluation of earthquakes was started. The Earthquake Research Committee is verifying the results of the long-term evaluation and re-evaluating the earthquakes in the region (the Chishima Trench).

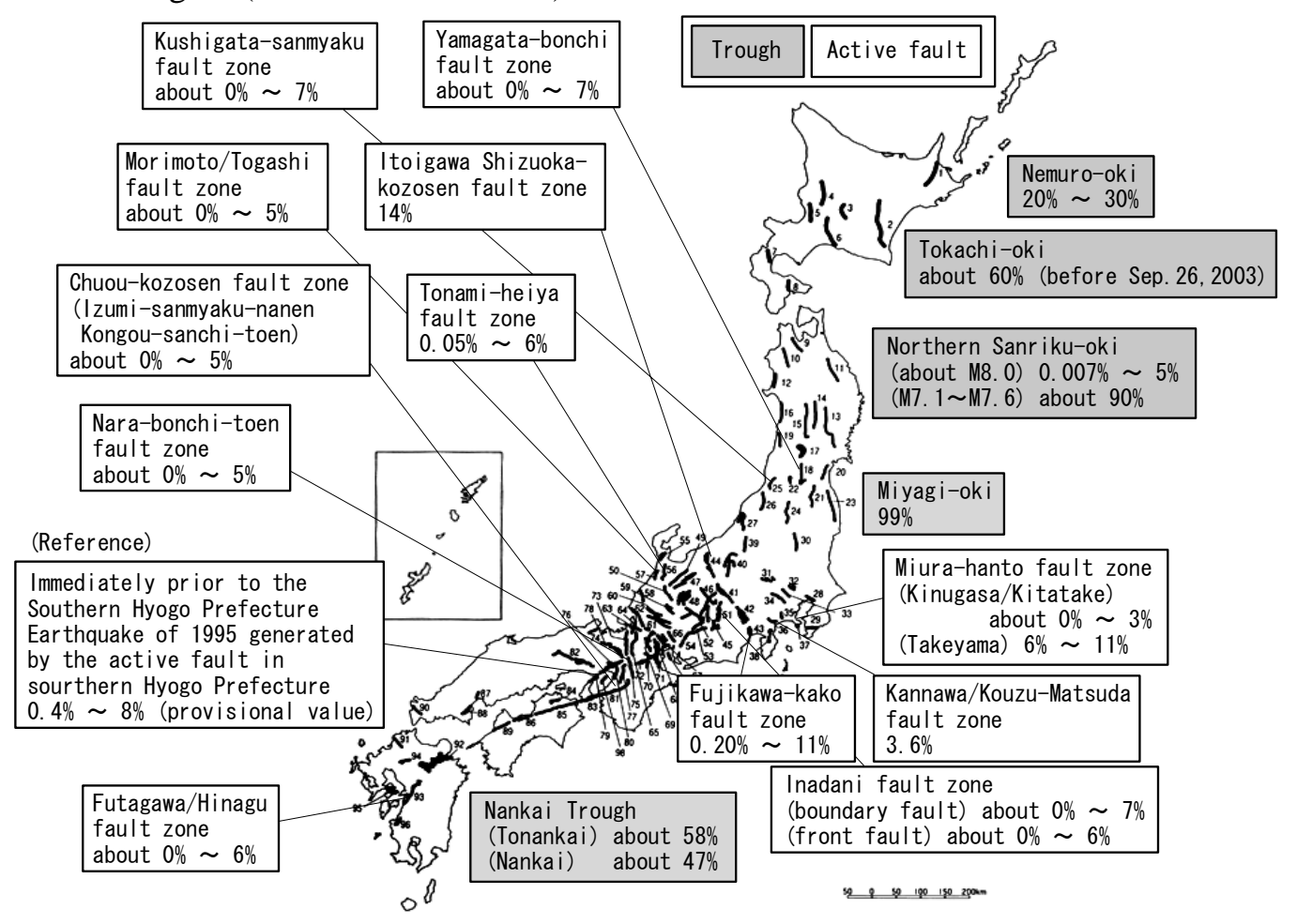

Fig. 3 Major fault zones and surrounding sea regions in evaluations announced to date (Probabilities of large-scale earthquakes over the next thirty years)

\section{GENERAL SEISMIC HAZARD MAPS}

As a part of the comprehensive assessment of seismic activity, the Earthquake Research Committee is 
planning to create a "General Seismic Hazard Map covering the whole of Japan" by March 2005, which is comprised of a probabilistic seismic hazard map of the whole of Japan and scenario earthquake maps of major earthquakes. In order to create the maps related surveys and research will be conducted at survey, observation and research institutions. In particular (1) elucidation of the characteristics of inland and coastal earthquakes, and systematization of information, (2) elucidation of the characteristics of deep-sea earthquakes, and systematization of information, (3) long-term probability assessment of the occurrence of earthquakes, (4) improvement of methods of predicting strong tremors, and (5) underground structure surveys will be promoted.

A probabilistic seismic hazard map shows the predicted likelihood of a strong ground motion occurring in a given area within a given period of time. The Earthquake Research Committee published trial reports for the limited area of Yamanashi Prefecture in 2002, Northern Japan in 2003, and Western Japan in 2004 (Subcommittees for Long-term Evaluations and for Evaluations of Strong Ground Motion, 2002, 2003, 2004). Also, there is a scenario earthquake map, which shows the predicted strong ground motion in a given area due to a given earthquake. The Earthquake Research Committee has published evaluation reports for 8 major earthquakes as of March 2004. Figures 4 and 5 show the examples of these two types of seismic hazard maps (The Earthquake Research Committee, 2003; Subcommittees for Long-term Evaluations and for Evaluations of Strong Ground Motion, 2004).

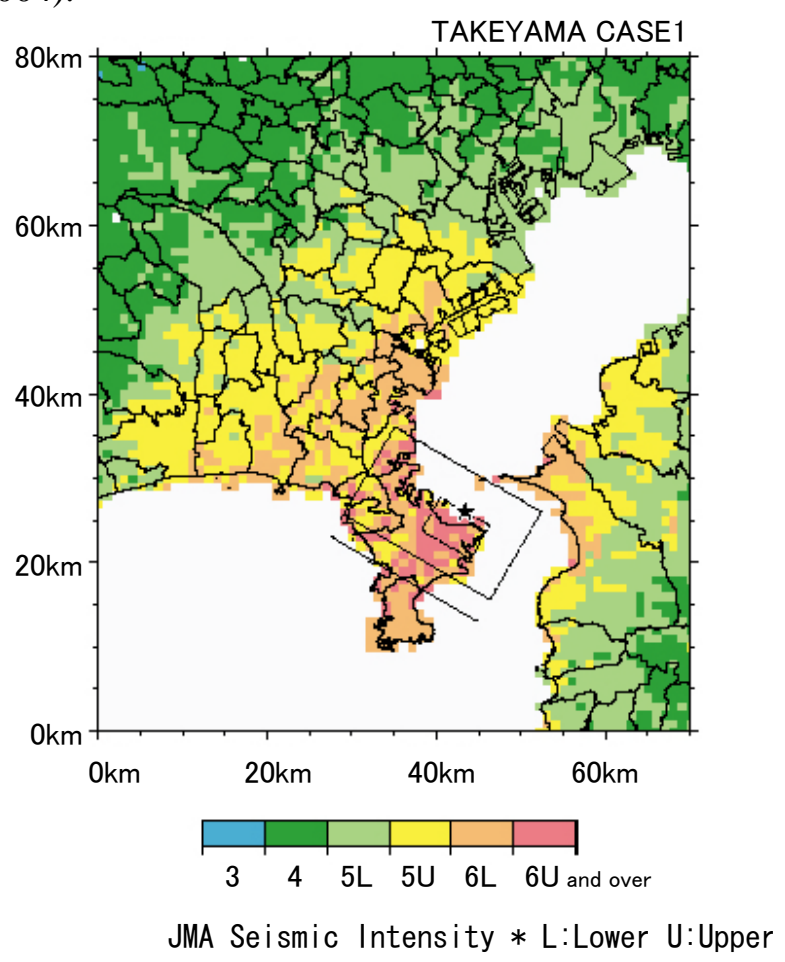

Fig.4 An example of scenario earthquake maps (Takeyama fault, Miura-hanto fault zone)

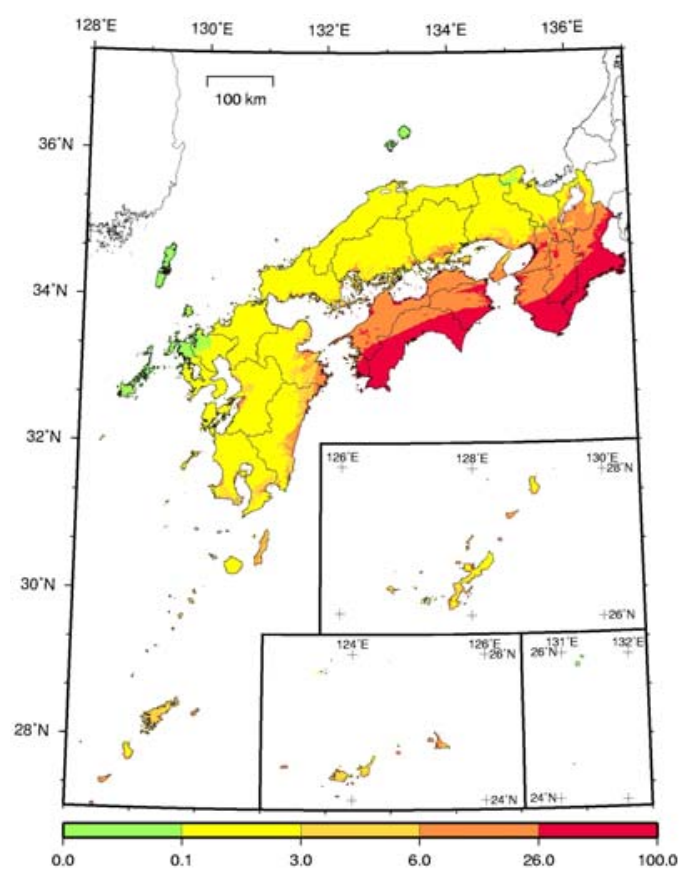

Probability of exceedance of JMA seismic intensity 6 Lower in the next 30 years

Fig.5 A trial map of probabilistic seismic hazard maps (Western Japan)

Figure 6 shows the probabilistic seismic hazard map of northern Japan (Subcommittees for Long-term Evaluations and for Evaluations of Strong Ground Motion, 2003) and locations where JMA intensity 6 lower was observed at the Tokachi-oki earthquake of 2003 (M8.0). Those points which suffered from strong ground shaking with a seismic intensity of 6 lower were evaluated as having a relatively high probability of exceedance of intensity 6 lower (6\% and above). 


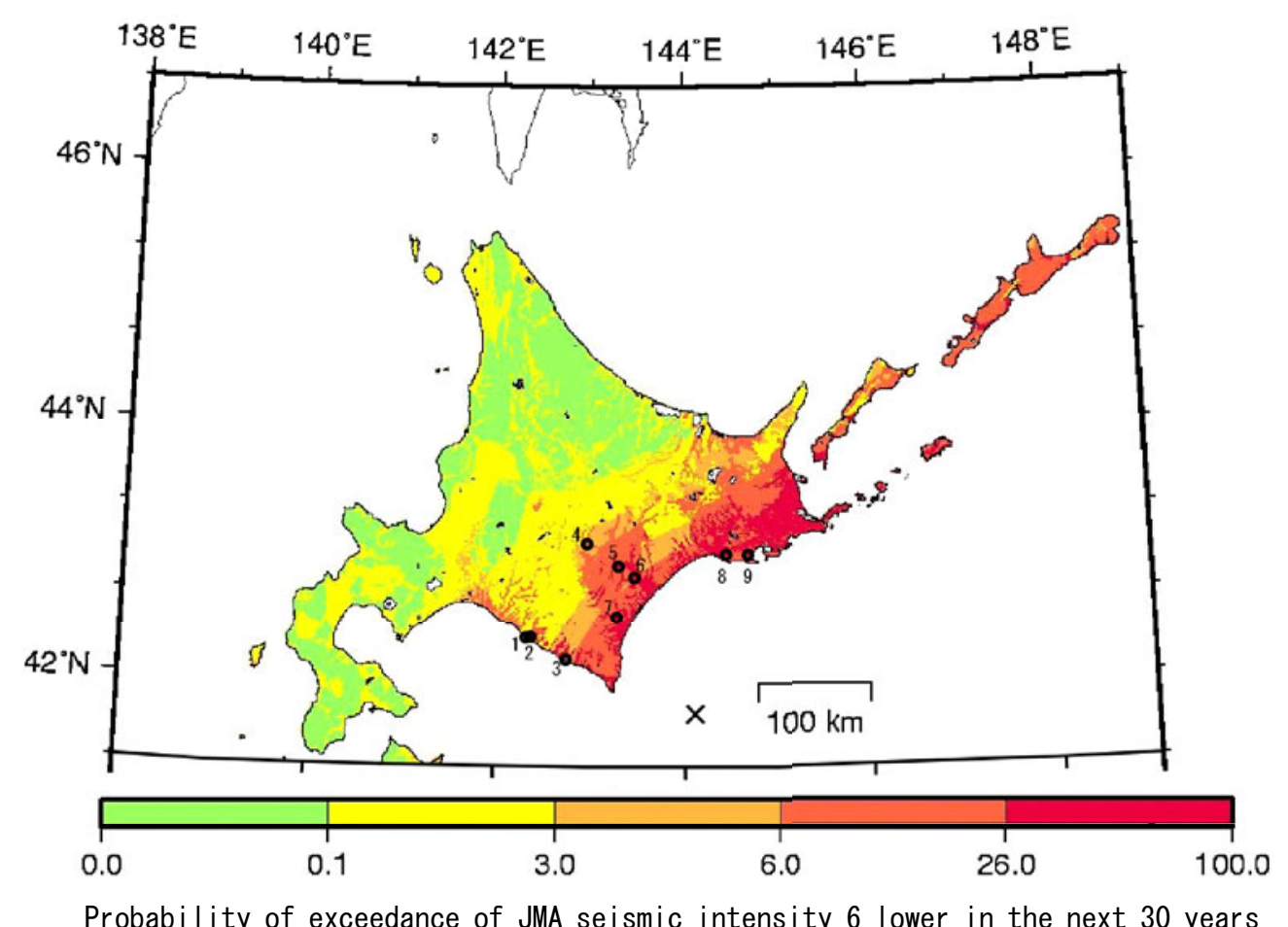

Fig.6 Probabilistic seismic hazard map of Hokkaido, Japan and the locations where seismic intensity 6 lower was observed at the Tokachi-oki earthquake of 2003 (M8.0). Open circles and a cross indicate the points with a seismic intensity of 6 lower and the epicenter, respectively.

\section{PUBLIC ANNOUNCEMENTS}

A subcommittee was established under the Policy Committee to consider ways of applying the results of earthquake research to the public.

For example, the following revisions were proposed as a means of making the results of assessments of the potential for earthquake occurrence easier to understand to the public (Fig.7).

The Headquarters for Earthquake Research Promotion is also engaged in providing information regarding seismic activity and crustal movements in Japan in a variety of formats easily understandable by the public.

\section{Itoigawa Shizuoka-kozosen fault zone}

\section{(before revision)}

There is a high probability that an M8 class (M7 1/2 M8 1/2)

earthquake will occur within the next several hundred years in the area

along the Gofukuji fault.

(after revision)

\begin{tabular}{|l|c|c|}
\hline Forecasted scale of earthquake & \multicolumn{2}{|c|}{ M8 class $(71 / 2 \sim 81 / 2)$} \\
\hline Probability of earthquake & 30 years & $14 \%$ \\
\cline { 2 - 3 } occurrence & 50 years & $23 \%$ \\
\cline { 2 - 3 } & 100 years & $41 \%$ \\
\hline
\end{tabular}

This fault is in the group of major faults with the highest probability of an earthquake occurring within the next thirty years.(3 ranks)

Fig.7 An example of the reports of long-term evaluation 


\section{REFERENCES}

Subcommittees for Long-term Evaluations and for Evaluations of Strong Ground Motion, the Earthquake Research Committee (2002). Preliminary version of Probabilistic Seismic Hazard Map (Specific Area), http://www.jishin.go.jp/main/index-e.html.

Subcommittees for Long-term Evaluations and for Evaluations of Strong Ground Motion, the Earthquake Research Committee (2003). Preliminary version of Probabilistic Seismic Hazard Map (Specific Area - Northern Japan), http://www.jishin.go.jp/main/index.html (in Japanese).

Subcommittees for Long-term Evaluations and for Evaluations of Strong Ground Motion, the Earthquake Research Committee (2004). Preliminary version of Probabilistic Seismic Hazard Map (Specific Area - Western Japan), http://www.jishin.go.jp/main/index.html (in Japanese).

The Earthquake Research Committee (1998). Seismic activity in Japan - regional perspectives on the characteristics of destructive earthquakes -, http://www.jishin.go.jp/main/index-e.html.

The Earthquake Research Committee (2003). On the strong ground motion evaluation methods of active faults of Miura Peninsula, http://www.jishin.go.jp/main/index.html (in Japanese).

The Earthquake Research Committee (2003). Long-term evaluation of earthquake in the Chishima Trench, http://www.jishin.go.jp/main/index.html (in Japanese).

The Headquarters for Earthquake Research Promotion (1999). The promotion of earthquake research, - comprehensive basic policies for the promotion of seismic research through the observation, measurement, and survey of earthquakes -, http://www.jishin.go.jp/main/index-e.html.

(Submitted: April 19, 2004)

(Accepted: June 22, 2004)

Copyright JAEE 